\title{
Calnexin regulated gonadotropin-releasing hormone receptor plasma membrane expression
}

\author{
Shaun P Brothers ${ }^{1,2}$, Jo Ann Janovick ${ }^{1}$ and P Michael Conn ${ }^{1,2,3}$ \\ ${ }^{1}$ Division of Neuroscience and Reproductive Sciences, Oregon National Primate Research Center, Departments of ${ }^{2}$ Physiology and Pharmacology, ${ }^{3}$ Cell and Developmental Biology, \\ Oregon Health and Science University, ONPRC/OHSU, 505 NW 185th Avenue, Beaverton, Oregon 97006, USA \\ (Requests for offprints should be addressed to P Michael Conn; Email: connm@ohsu.edu)
}

\begin{abstract}
A significant proportion of human gonadotropin-releasing hormone receptors (GnRHRs) are normally retained in the endoplasmic reticulum (ER); however, nearly all rat GnRHRs are routed to the plasma membrane. When mutations are introduced into either receptor, considerably more of the proteins are recognized by the quality control system (QCS) as misfolded and retained compared with wild-type (WT) receptor, resulting in decreased signaling in the presence of agonist. Calnexin, a component of the QCS, decreased plasma membrane expression of the GnRHRs, an effect that was mediated by a physical interaction between the receptor and the calnexin. Only the human receptor showed reduced signaling because it had fewer spare receptors compared with the rat GnRHR, allowing calnexin to affect signaling. Calnexin did not affect receptor signaling when $\mathrm{K}^{191}$ was deleted from the human WT GnRHR. Removal of this amino acid decreases receptor misfolding and increases plasma membrane expression. $\mathrm{K}^{191}$ is not present in the rat WT GnRHR. A pharmacological chaperone that corrects GnRHR misfolding, increased expression of the human WT GnRHR in the presence of calnexin. Calnexin apparently retains misfolded $\mathrm{GnRHRs}$ but routes correctly folded receptors to the plasma membrane. Mutation of a calnexin protein kinase $\mathrm{C}$ consensus phosphorylation site promoted increased retention of the human GnRHR, suggesting that calnexin phosphorylation controls the retention mechanism. We conclude that a proportion of the human and the rat WT GnRHR appears to be retained in the ER by calnexin, an effect that decreases GnRHR signaling capacity.
\end{abstract}

Journal of Molecular Endocrinology (2006) 37, 479-488

\section{Introduction}

An evolutionary trend among gonadotropin-releasing hormone receptor (GnRHR) proteins results in progressively decreased expression at the plasma membrane (Janovick et al. 2003, 2006, Knollman et al. 2005). In avian and piscine GnRHRs, for example, an intracellular carboxyl terminal extension (c-tail) is associated with high plasma membrane expression. A chimera in which this extension is added to the human GnRHR results in elevated expression at the plasma membrane compared with unmodified human wild-type (WT) GnRHR (Lin et al. 1998). Among mammalian GnRHRs, there is an 'extra' amino acid at position 191 that is not present in rats or mice (Sealfon et al. 1997, Arora et al. 1999, Maya-Nunez et al. 2000). This amino acid addition is $\mathrm{K}^{191}$ in primates and $\mathrm{Glu}^{191}$ in bovine, ovine, porcine, equine, and canine receptors (Sealfon et al. 1997). In humans, deletion of the $\mathrm{K}^{191}$ results in greater plasma membrane expression of the receptors (Arora et al. 1999, Maya-Nunez et al. 2000).

Pharmacological chaperones ('pharmacoperones') correct protein misfolding and allow molecules that would otherwise be retained in the endoplasmic reticulum (ER) to route to the plasma membrane
(Ulloa-Aguirre et al. 2004, Castro-Fernandez et al. 2005). The pharmacoperone, IN3, increases plasma membrane expression of most naturally occurring mutant GnRHRs, since these are frequently misfolded proteins and retained in the ER (Conn et al. 2002, Couzin 2002, Janovick et al. 2002, Brothers et al. 2003, 2004, Ulloa-Aguirre et al. 2004, Castro-Fernandez et al. 2005). IN3 also increases human WT GnRHR expression at the plasma membrane, an effect not observed for the rodent GnRHRs (Conn et al. 2002, Janovick et al. 2002, Brothers et al. 2003, 2004).

Quality control system (QCS) chaperones in the ER may be responsible for retention of the GnRHR. Calnexin is one such chaperone that binds to newly synthesized proteins for quality assessment (Vassilakos et al. 1998, Ellgaard \& Frickel 2003). Calnexin is thought to regulate routing of proteins by preventing protein aggregation (Hebert et al. 1996), allowing properly folded proteins to reach sites associated with their function (Schrag et al. 2003, Kleizen \& Braakman 2004), by retaining misfolded proteins in the ER and routing them to degradation pathways (Liu et al. 1999, Molinari et al. 2003, Oda et al. 2003). The calnexin-protein interaction may depend on the phosphorylation state of the calnexin cytoplasmic carboxyl terminus (Roderick et al. 2000).

DOI: $10.1677 / j m e .1 .02142$ Online version via http://www.endocrinology-journals.org 
Calnexin was expressed with WT and mutant GnRHRs to determine whether it is responsible for quality control of GnRHRs. We demonstrate a role for calnexin mediation of GnRHR retention and describe features in both the receptor and the calnexin that are associated with retention.

\section{Materials and methods}

\section{Materials}

The GnRH analog, D-tert-butyl-Ser ${ }^{6}$-des-Gly ${ }^{10}$-Pro ${ }^{9}$-ethylamide-GnRH (Buserelin, Hoechst-Roussel Pharmaceuticals, Somerville, NJ, USA), (2S)-2-[5-[2-(2-azabi cyclo[2.2.2] oct-2-yl)-1,1-dimethyl-2-oxoethyl]-2-(3,5-di methylphenyl)-1 $H$-indol-3-yl]- $\mathrm{N}$-(2-pyridin-4-ylethyl) propan-1-amine (IN3, Merck \& Co.), myo-[2- $\left.{ }^{3} \mathrm{H}(\mathrm{N})\right]-$ inositol and $\mathrm{Na}\left[{ }^{125} \mathrm{I}\right]$ (Perkin-Elmer, Boston, MA, USA; NET-114A and NEZ-033L), competent cells (Promega), PCR primers, Dulbecco's Minimal Essential Medium (DMEM), OPTI-MEM, lipofectamine, PBS, and pcDNA3.1 (Invitrogen), endofree maxi-prep kits (Qiagen), rat calnexin (a kind gift from Dr Larry Tjoelker; Tjoelker et al. 1994) and human calnexin, cDNA (Open Biosystems, Huntsville, AL, USA, MHS1011-60083), SMARTpool human calnexin siRNA and siCONTROL non-targeting pool siRNA (Dharmacon Inc., Lafayette, CO, USA), mouse monoclonal anti-hemagglutinin epitope tag (HA) antibody (12CA5, Roche Applied Sciences), rabbit polyclonal anticalnexin (H-70) antibody (sc-11397; Santa Cruz Biotechnology, Santa Cruz, CA, USA) were obtained as indicated. Other reagents were obtained from commercial sources and were of the highest degree of purity available. GnRHR and calnexin cDNA were prepared using site-directed mutagenesis, as reported (Brothers et al. 2004). Forward and reverse primers for subcloning calnexin cDNA into pcDNA3.1, obtained from the Mammalian Genes Collection(MGC) contained KpnI restriction enzyme site sequence, Kozak's consensus sequence followed by the ATG start site and 18 nucleotides of the $\mathrm{N}$-terminus of the protein coding sequence (forward primer) or Xbal followed by the reverse complement stop codon and 18 nucleotides of the C-terminus of the complementary protein coding sequence (reverse primer). The identity of all the cDNA mutants and the correctness of all PCR-derived coding sequences were verified by Dye Terminator Cycle Sequencing, according to the manufacturer's instructions (Perkin-Elmer, Foster City, CA, USA).

\section{Transient transfection and co-transfection}

COS-7 cells were cultured, plated, and transfected as previously reported (Brothers et al. 2004). Cells were transfected with $25 \mathrm{ng}$ (unless indicated) WT human or rat GnRHR, or mutant GnRHR and pcDNA3.1 without insert ('empty vector') or WT/mutant calnexin cDNA (75 ng/well), as indicated, and $1 \mu \mathrm{l}$ lipofectamine in $0 \cdot 125 \mathrm{ml}$ OPTI-MEM (room temperature), according to the manufacturer's instructions. Empty vector (pcDNA3.1, without insert) was included to bring the total cDNA to $100 \mathrm{ng} /$ well. The concentration of cDNA that does not interfere with the transfection efficiency is $100 \mathrm{ng} /$ well (Janovick et al. 2003, Brothers et al. 2004). Where indicated, $1.5 \mathrm{pMol}$ siRNA $/ 5 \times 10^{4}$ cells was included in the transfection mixture, according to the manufacturer's instructions. Five hours after transfection, $0 \cdot 125 \mathrm{ml}$ DMEM with $20 \%$ fetal bovine serum and $20 \mu \mathrm{g} / \mathrm{ml}$ gentamicin was added to the wells.

\section{Inositol phosphate (IP) assays}

Cells received IN3 treatments as previously reported (Brothers et al. 2004), where indicated. Cells were washed, then 'pre-loaded' for $18 \mathrm{~h}$ with $1 \mu \mathrm{Ci}$ myo$\left[2{ }^{3} \mathrm{H}(\mathrm{N})\right]$-inositol in $0.25 \mathrm{ml}$ DMEM (prepared without inositol; Brothers et al. 2004). The cells were then washed twice with $0.25 \mathrm{ml}$ DMEM containing $5 \mathrm{mM}$ $\mathrm{LiCl}$ (without inositol), treated for $2 \mathrm{~h}$ with $0.25 \mathrm{ml}$ of the indicated Buserelin concentration in the same medium ( $\mathrm{LiCl}$ prevents inositol phosphate (IP) degradation). Total IPs were determined as described previously (Huckle \& Conn 1987, Brothers et al. 2004). Extracellular $\left(\mathrm{EC}_{50}\right)$ and maximal IP production were calculated using Sigma Plot 8.02 (Jandel Scientific Software, Chicago, IL, USA). Using similar affinities for unlabeled Buserelin and $\mathrm{EC}_{50}$ values averaged from at least three independent experiments, the spare receptors (the percentage of unoccupied receptors at half maximal response, in this case IP production) were calculated (Zhu 1993).

\section{Binding assays}

Cells were cultured and plated in growth medium as described previously, except that $10^{5}$ cells in $0.5 \mathrm{ml}$ growth medium were added to 24-well Costar cell culture plates (cell transfection and medium volumes were doubled accordingly). After $23 \mathrm{~h}$ transfection, the medium was removed and replaced with $0.5 \mathrm{ml}$ fresh growth medium. After $27 \mathrm{~h}$ transfection, the cells were washed twice with $0.5 \mathrm{ml}$ DMEM containing $0.1 \%$ BSA and $20 \mu \mathrm{g} / \mathrm{ml}$ gentamicin, then $0.5 \mathrm{ml}$ DMEM was added. After $18 \mathrm{~h}$, cells were washed twice with $0.5 \mathrm{ml}$ DMEM $/ 0 \cdot 1 \%$ BSA $/ 10 \mathrm{mM}$ HEPES, and then a range of concentrations of $\left[{ }^{125} \mathrm{I}\right]$-Buserelin (from $2 \cdot 5 \times 10^{5}$ to $8 \times 10^{6}$ c.p.m. $/ \mathrm{ml}$ ) in $0.5 \mathrm{ml}$ of the same medium were added to the cells and allowed to incubate at room 
temperature for $90 \mathrm{~min}$ (Brothers et al. 2002). After $90 \mathrm{~min}$, the media were removed and radioactivity was measured as described previously (Brothers et al. 2003). To determine non-specific binding, the same concentrations of radioligand were added to similarly transfected cells in the presence of $10 \mu \mathrm{M}$ unlabeled GnRH. Saturation binding curve fits and calculations were computed using the SigmaPlot 8.02 (Jandel Scientific Software), a non-linear one-site binding model was used to calculate $K_{\mathrm{d}}$ and $B_{\max }$ values (Klotz 1982). Binding data was also transformed into Scatchard plots.

\section{Co-immunoprecipitation and western blotting}

Cells were cultured and plated in growth medium as described previously, except that $4 \times 10^{6}$ cells in $2 \mathrm{ml}$ growth medium were added to six-well Costar cell culture plates (cell transfection and medium volumes were adjusted accordingly). After $23 \mathrm{~h}$ transfection, the medium was removed and replaced with $2 \mathrm{ml}$ fresh growth medium. After $27 \mathrm{~h}$ transfection, the cells were washed twice with $2 \mathrm{ml}$ DMEM containing 0.1\% BSA and $20 \mu \mathrm{g} / \mathrm{ml}$ gentamicin then $2 \mathrm{ml}$ DMEM was added. For immunoprecipitations, cells were washed twice with $2 \mathrm{ml}$ ice-cold PBS containing protease inhibitors, then $0.5 \mathrm{ml}$ radio immunoprecipitation buffer with protease inhibitors was placed on the cells for $30 \mathrm{~min}$ at $4{ }^{\circ} \mathrm{C}$. Immunoprecipitations were carried out as described previously (Firestone \& Winguth 1990, Castro-Fernandez et al. 2002). For siRNA treated cells, after $18 \mathrm{~h}$, cells were washed twice with ice-cold PBS and frozen, then thawed in the presence of $0.5 \mathrm{ml} 2 \times$ sample buffer. SDS-polyacrylamide gels $(8 \%)$ and western transfers of cell lysates to nitrocellulose paper (Hoefer Scientific Instruments, San Francisco, CA, USA) were performed as described previously (Conn et al. 1992, Castro-Fernandez et al. 2002). Polyclonal calnexin antibody was used at a 1:200 titer. Control cells for co-immunoprecipitations were transfected with untagged WT GnRH receptor cDNA. The molecular weights of the protein bands were calculated from standards that were colorstained proteins ('rainbow markers') with the following molecular weights: myosin, $220 \mathrm{kDa}$; phosphorylase b, $97.4 \mathrm{kDa}$; BSA, $66 \mathrm{kDa}$; ovalbumin, $46 \mathrm{kDa}$; carbonic anhydrase, $30 \mathrm{kDa}$; trypsin inhibitor, $21.5 \mathrm{kDa}$; lysozyme, $14 \cdot 3 \mathrm{kDa}$ (Amersham Pharmacia Biotech). Western blot band optical densities were quantified using National Institute of Health (NIH) image 1.62 (http:// rsb.info.nih.gov/nih-image/).

\section{Statistics}

Each experiment was repeated a minimum of three times. Replicates of at least four data points for each treatment group within an experiment were analyzed with one-way ANOVA followed by paired Student's $t$-test for individual comparisons (SigmaStat 3.0, Jandel Scientific Software; $P<0.05$ was considered significant).

\section{Results}

\section{Calnexin reduces plasma membrane expression of the human and the rat GnRHRs}

Human or rat GnRH receptors were co-transfected with calnexin in order to assess the effect on plasma membrane expression (PME) using a radioligand binding assay. Co-transfecting calnexin cDNA with the human or rat GnRHR did not alter $K_{\mathrm{d}}$ of either receptor (Fig. 1A or B). Human GnRHR PME ( $\left.B_{\max }\right)$ decreased by $47 \pm 3 \% \quad(P<0 \cdot 05)$ in the presence of calnexin compared with cells co-transfected with empty vector (Fig. 1B). Rat GnRHR PME decreased by $40 \pm 6 \%$ $(P<0 \cdot 05)$ when calnexin was co-transfected. Non-linear saturation binding curves used to calculate $K_{\mathrm{d}}$ and $B_{\max }$ were also transformed into Scatchard plots (Zhu 1993; Fig. 1C and D).

\section{Dose-response relation of human and rat GnRHRs co-transfected with calnexin}

Maximal IP production and $\mathrm{EC}_{50}$ values were determined for the human and the rat GnRHRs in the absence or presence of calnexin. There was a significant decrease in the maximal IP production from cells co-transfected with the human receptor and the calnexin compared with cells without added calnexin $(P<0 \cdot 05)$. Despite the reduction in PME of the rat GnRH receptor, there was no observable effect of calnexin on maximal IP production $(P>0 \cdot 05$; Fig. 2A).

Calnexin did affect the $\mathrm{EC}_{50}$ of both human and rat receptors, in both cases more ligand was required to achieve a $50 \%$ response (Fig. 2B). The $\mathrm{EC}_{50}$ of the human GnRHR increased from $400 \pm 47$ to $640 \pm 22 \mathrm{pM}$ $(P<0 \cdot 05)$ when calnexin was co-transfected. The $\mathrm{EC}_{50}$ of the rat GnRHR increased from $119 \pm 4$ to $202 \pm 20$ pM $(P<0 \cdot 05)$ when calnexin was co-transfected.

The $\mathrm{EC}_{50}$ values were used to calculate the percentage of unoccupied receptors at half maximal IP production (Gavel \& von Heijne 1990). The human GnRHR showed $38.4 \pm 5.0 \%$ spare receptors at the $\mathrm{EC}_{50}$ ligand concentration, but when calnexin was co-transfected with the human receptor, the quantity of spare receptors fell to $16.5 \pm 1.6 \%(P<0.05)$. Similarly, the rat GnRHR had $76 \cdot 4 \pm 0.7 \%$ spare receptors at the $\mathrm{EC}_{50}$ ligand concentration, but only $63 \cdot 1 \pm 3 \cdot 1 \%$ spare receptors with calnexin $(P<0 \cdot 05)$. The rat GnRHR appears to express sufficient numbers of receptors 


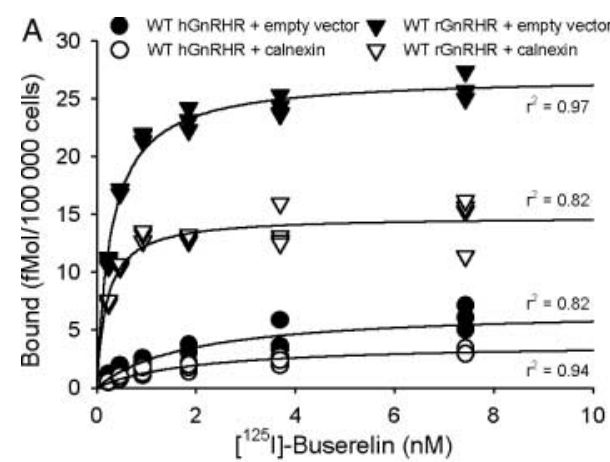

B
\begin{tabular}{|c|ccc|}
\hline $\begin{array}{c}\text { Cells } \\
\begin{array}{c}\text { Transfected } \\
\text { With: }\end{array}\end{array}$ & $\begin{array}{c}\mathrm{Kd} \\
(\mathrm{nM})\end{array}$ & $\begin{array}{c}\text { Bmax } \\
(\mathrm{fMol} / 100,000 \\
\text { cells })\end{array}$ & $\begin{array}{c}\text { Average \# } \\
\text { receptors } \\
/ \text { cell }\end{array}$ \\
\hline $\begin{array}{c}\text { WT hGnRHR } \\
+ \text { empty vector }\end{array}$ & $1.8 \pm 0.03$ & $5.6 \pm 0.4^{\mathrm{a}}$ & $33000 \pm 2200^{\mathrm{a}}$ \\
\hline $\begin{array}{c}\text { WT hGnRHR } \\
+ \text { calnexin }\end{array}$ & $2.1 \pm 0.1$ & $3.0 \pm 0.3^{\mathrm{a}}$ & $18000 \pm 1600^{\mathrm{a}}$ \\
\hline $\begin{array}{c}\text { WT rGnRHR } \\
+ \text { empty vector }\end{array}$ & $0.3 \pm 0.02$ & $21.2 \pm 1.8^{\mathrm{a}}$ & $128000 \pm 11000^{\mathrm{a}}$ \\
\hline $\begin{array}{c}\text { WT rGnRHR } \\
+ \text { calnexin }\end{array}$ & $0.3 \pm 0.04$ & $12.6 \pm 1.2^{\mathrm{a}}$ & $76000 \pm 6900^{\mathrm{a}}$ \\
\hline
\end{tabular}
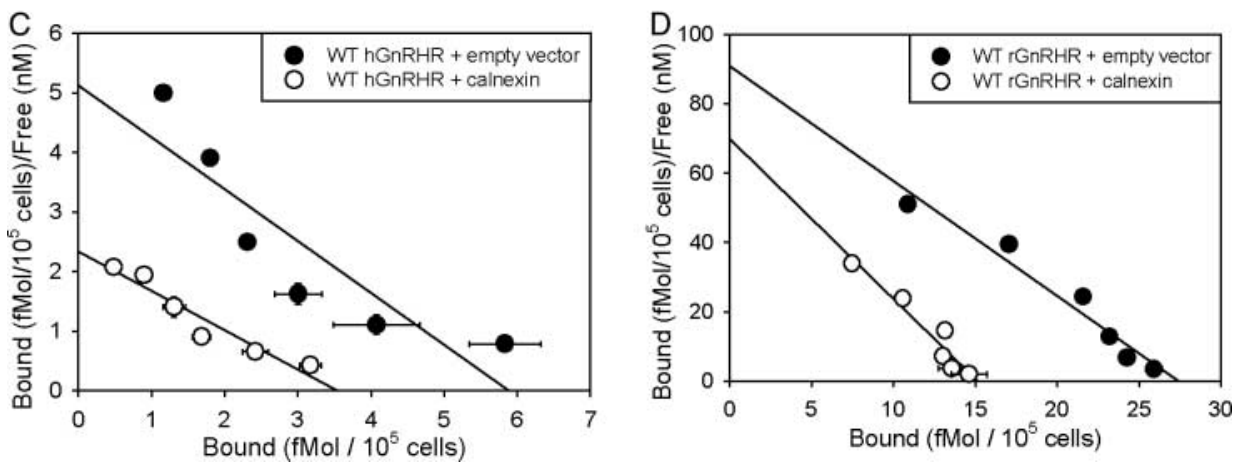

Figure 1 Saturation binding analysis in cells transfected with human and rat WT receptors and calnexin. (A) A one-site non-linear saturation binding curve generated in cells expressing the indicated proteins. (B) Analysis of three independent saturation binding experiments. $K_{\mathrm{d}}$ and $B_{\max }$ values were calculated from non-linear binding plots. The values for average number of receptors per cell were calculated from $B_{\max }$ values. (C) and (D) Scatchard binding plots were used for visual comparison purposes. ('a' indicates $P<0.05$ comparing between empty vector and calnexin treatment groups with the same receptors).

at the plasma membrane to saturate the signal transduction machinery, even when there is a $40 \%$ reduction in PME.

\section{Calnexin co-immunoprecipitates with the GnRHR}

HA-tagged human and rat WT GnRH receptors, as well as the E90K mutant of the hGnRHR were co-transfected with calnexin. If anti-HA antibody was used to immunoprecipitate the tagged receptors, then the western blots of the immunoprecipitates were probed with anti-calnexin antibody. When the receptors were transfected alone or in the presence of calnexin cDNA, calnexin co-immunoprecipitated with the receptor, although when calnexin cDNA was co-transfected with the receptor, there appeared to be more calnexin protein bound to the receptors (Fig. 3A). When WT (i.e. untagged) GnRH receptors were transfected into cells immunoprecipitated with the anti-HA antibody, there was no visible calnexin staining (not shown). Cellular calnexin was then immunoprecipitated and subjected to western-blot analysis. When the blots were probed for the presence of the HA-tagged GnRH receptor, there was little specific staining. Presumably this is due to the fact that calnexin is a chaperone for a great number of proteins besides the GnRH receptor that compete for calnexin binding.

\section{Effect of calnexin on cells expressing similar amounts of human and rat GnRHRs}

To determine whether calnexin affected the IP production of rat $\mathrm{GnRH}$ receptors expressed at approximately the same level as human receptors, cells were transfected with $25 \mathrm{ng}$ human GnRHR cDNA and $2 \mathrm{ng}$ rat GnRHR cDNA. Cells transfected with $2 \mathrm{ng}$ rat GnRHR had approximately the same IP production as $25 \mathrm{ng}$ human GnRHR transfected cells (not shown). Therefore, a $\sim 12 \cdot 5$-fold reduction in DNA was required to achieve a similar level of IP production with the rat GnRHR. As expected, when the $2 \mathrm{ng}$ rat GnRHR was co-transfected with calnexin, there was a significant reduction in the IP response (Fig. 3B).

\section{siRNA knockdown of calnexin and western blotting}

To determine whether calnexin protein production (rather than a non-specific effect related to calnexin cDNA transfection) was required for the inhibitory effect on PME, calnexin siRNA was used to knock down 

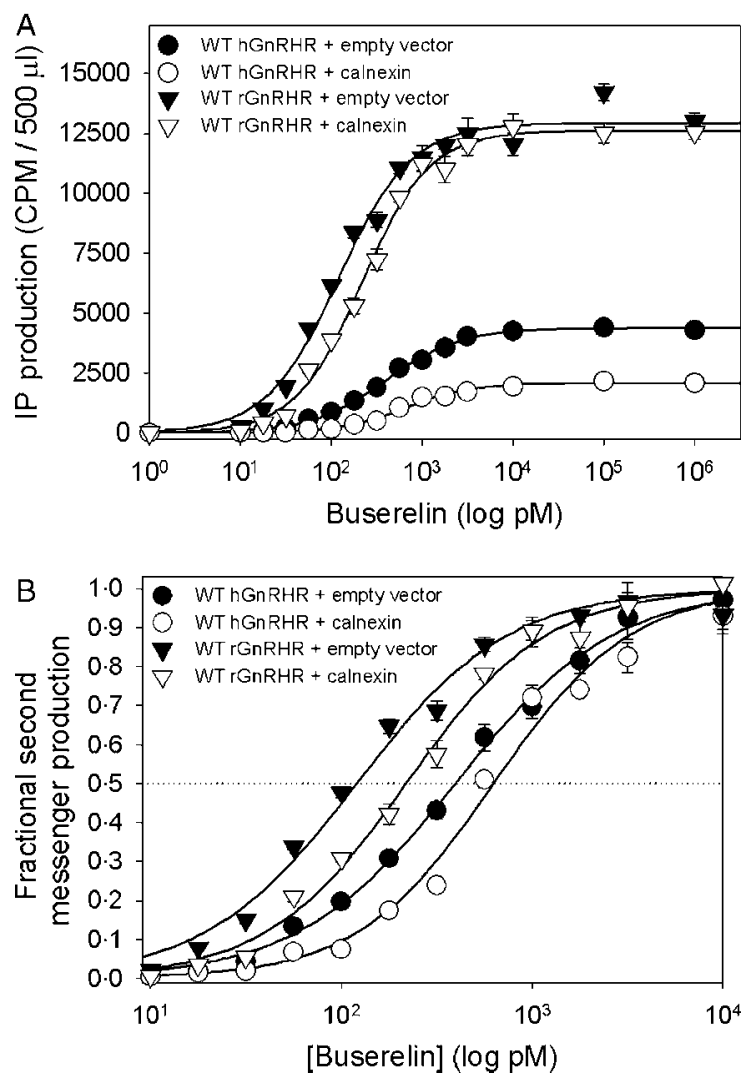

Figure 2 Dose-response relation of the WT human and rat GnRHR in the presence of calnexin. (A) Dose-response curves for the WT human and rat GnRHRs co-transfected with empty vector (closed symbols) or calnexin (open symbols). Cells were stimulated with a range of the GnRHR agonist, Buserelin, from 1 $\mathrm{pM}$ to $1 \mu \mathrm{M}$. IP production in the absence of ligand was subtracted and typically ranged from 100 to 120 c.p.m./500 $\mu$ l. $N=6$ for each data point. (B) Data points were normalized by dividing by the calculated maximal IP production in each treatment group. The dotted line indicates where half of the maximal response is achieved. $\mathrm{EC}_{50}$ values from at least three independent experiments, such as the one represented here, were used to calculate spare receptors (the percentage of unoccupied receptors at half maximal response, in this case IP production).

calnexin mRNA. Western blotting showed that the siRNA directed against the human calnexin gene also knocked down endogenous calnexin protein expression but not to undetectable levels (Fig. 4A). When calnexin siRNA was co-transfected into cells with either the human or rat GnRHR, there was no measurable change in IP production, compared with cells transfected with control (non-targeting) siRNA $(P<0 \cdot 05$; Fig. 4B). This was a surprising result since we expected that the IP production from these cells would increase in the presence of calnexin siRNA. However, there was significantly increased IP production from calnexin siRNA-treated cells when calnexin siRA was co-transfected into cells with the human GnRHR and calnexin cDNA $(P<0 \cdot 05)$.
Either there is insufficient endogenous calnexin in COS-7 cells to retain significant quantities of the GnRHR, or, the endogenous calnexin in these African green monkey-derived COS-7 cells is not efficiently targeted by the calnexin siRNA that was designed to target the human mRNA sequence. When calnexin was transfected into cells, there was a $\sim$ tenfold increase in calnexin protein expression (Fig. 4C). When calnexin siRNA was transfected in cells, there was a significant decrease in calnexin protein levels with the siRNA, calnexin was knocked down by $85-90 \%(P<0 \cdot 05$; Fig. $4 \mathrm{C})$.

\section{Effect of calnexin on mutant receptors isolated from hypogonadotropic hypogonadism patients}

Calnexin was co-transfected with mutant GnRH receptors isolated from patients with hypogonadotropic hypogonadism (HH). The HH mutants hGnRHR $\left(\mathrm{N}^{10} \mathrm{~K}\right)$ (partially functional, fully rescuable by pharmacoperone), hGnRHR $\left(\mathrm{E}^{90} \mathrm{~K}\right)$ (non-functional, fully rescuable by pharmacoperone), $h \operatorname{GnRHR}\left(\mathrm{L}^{266} \mathrm{R}\right.$ ) (nonfunctional, partially rescuable by pharmacoperone), and $\operatorname{hGnRHR}\left(\mathrm{S}^{168} \mathrm{R}\right)$ (non-functional, non-rescuable by pharmacoperone) were selected for study because of these different responses to pharmacoperones.

As with the human WT GnRHR, when calnexin was co-transfected with hGnRHR $\left(\mathrm{N}^{10} \mathrm{~K}\right)$, IP production decreased compared with cells transfected with mutant alone (Fig. 5A). Interestingly, co-transfection of either the human WT GnRHR or hGnRHR $\left(\mathrm{N}^{10} \mathrm{~K}\right)$ with calnexin and treatment with IN3, yielded greater IP production than in IN3-treated cells expressing hGnRHR $\left(\mathrm{N}^{10} \mathrm{~K}\right)$ alone (Fig. 5A). This suggests that calnexin can increase PME of these pharmacoperone-stabilized receptors; however, the PME could not be confirmed with ligandbinding experiments after pharmacoperone treatment, presumably due to incomplete removal of the lipophilic competitive antagonist (not shown).

Whether calnexin was present or not, there was no measurable IP response above background from any of the non-functional GnRHR mutants isolated from $\mathrm{HH}$ patients (Fig. 5B-D). However, as with the human WT GnRHR, IP production from hGnRHR $\left(\mathrm{E}^{90} \mathrm{~K}\right)$-expressing cells increased in the presence of both calnexin and IN3 (Fig. 5B). Even in the presence of IN3, there was no change in the IP production by hGnRHR $\left(S^{168} R\right)$ or $\operatorname{hGnRHR}\left(\mathrm{L}^{266} \mathrm{R}\right)$ with calnexin compared with without calnexin co-transfection (Fig. $5 \mathrm{C}$ and D).

\section{$K^{191}$ modification and addition of the piscine carboxyl terminus (c-tail)}

Pre-mammalian GnRH receptors, such as fish and bird GnRHRs, have an extended carboxyl terminus which is truncated in the mammalian GnRHRs. This extended carboxyl terminus (c-tail), when added to the mammalian 
A
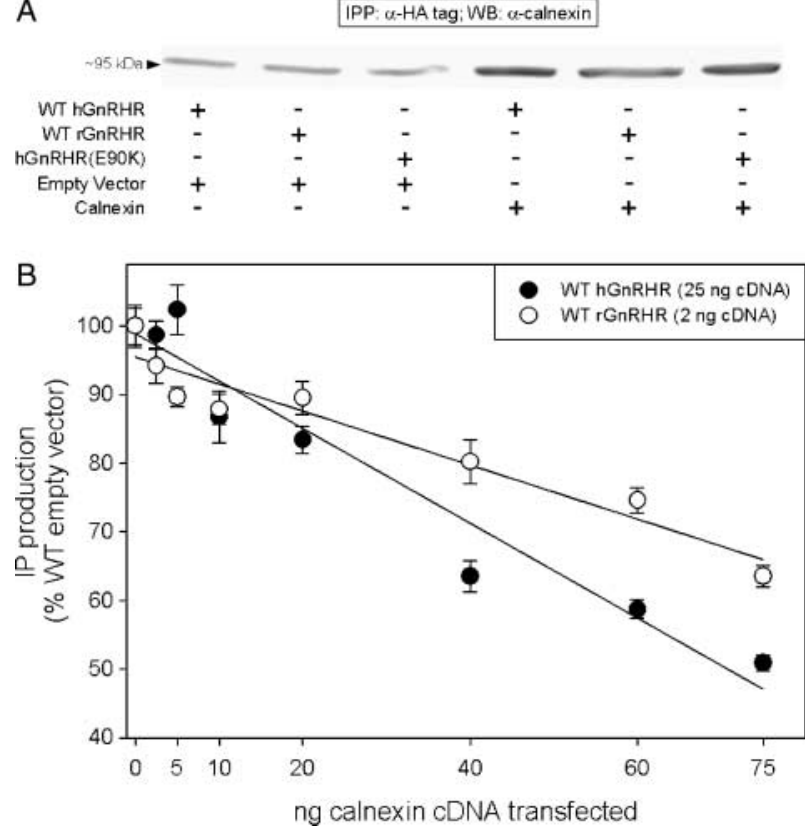

Figure 3 Co-immunoprecipitation of calnexin with the GnRHR and the effect of calnexin on fewer rat $\mathrm{GnRH}$ receptors. (A) The indicated $\mathrm{HA}$-tagged $\mathrm{GnRH}$ receptors were immunoprecipitated with anti-HA antibody, western blotted, then probed for the presence of calnexin protein. Arrow indicates a molecular weight of $95 \mathrm{kDa}$, the approximate apparent molecular weight of calnexin in a western blot. (B) Rat GnRHR (2 ng) and human GnRHR $(25 \mathrm{ng})$ were each co-transfected with indicated quantities of calnexin cDNA. IP production was measured in response to $100 \mathrm{nM}$ Buserelin. When WT GnRH receptors (i.e. untagged) were transfected into cells immunoprecipitated with the anti-HA antibody, there was no visible calnexin staining (not shown).

GnRHR, enhances plasma membrane expression (Lin et al. 1998, Arora et al. 1999, Maya-Nunez et al. 2000). Similarly, rat receptors (327 residues) lack the primate $\mathrm{K}^{191}$ residue that, when deleted from the human sequence (normally 328 residues), also results in increased receptor expression (Lin et al. 1998, Arora et al. 1999, Maya-Nunez et al. 2000).

When the c-tail was added to, or the $\mathrm{K}^{191}$ deleted from the human GnRHR, co-transfection with calnexin no longer affected IP production, either in the absence or presence of IN3 (Fig. 6B). This was also observed when both deletion of $\mathrm{K}^{191}$ and addition of c-tail were made to the human GnRHR (Fig. 6C).

Calnexin did not affect IP production, either in the absence or presence of IN3 (Fig. 6B) when the $\mathrm{K}^{191}$ was deleted, the c-tail added or both modifications made (Fig. 6A-C). Further, neither insertion of $\mathrm{K}^{191}$, nor addition of the c-tail to the rat GnRHR changed receptor-mediated IP production when co-transfected with calnexin (Fig. 6D-E). Addition of both the $\mathrm{K}^{191}$ and the c-tail also did not measurably change receptormediated IP production independent of calnexin co-transfection (Fig. 6F).
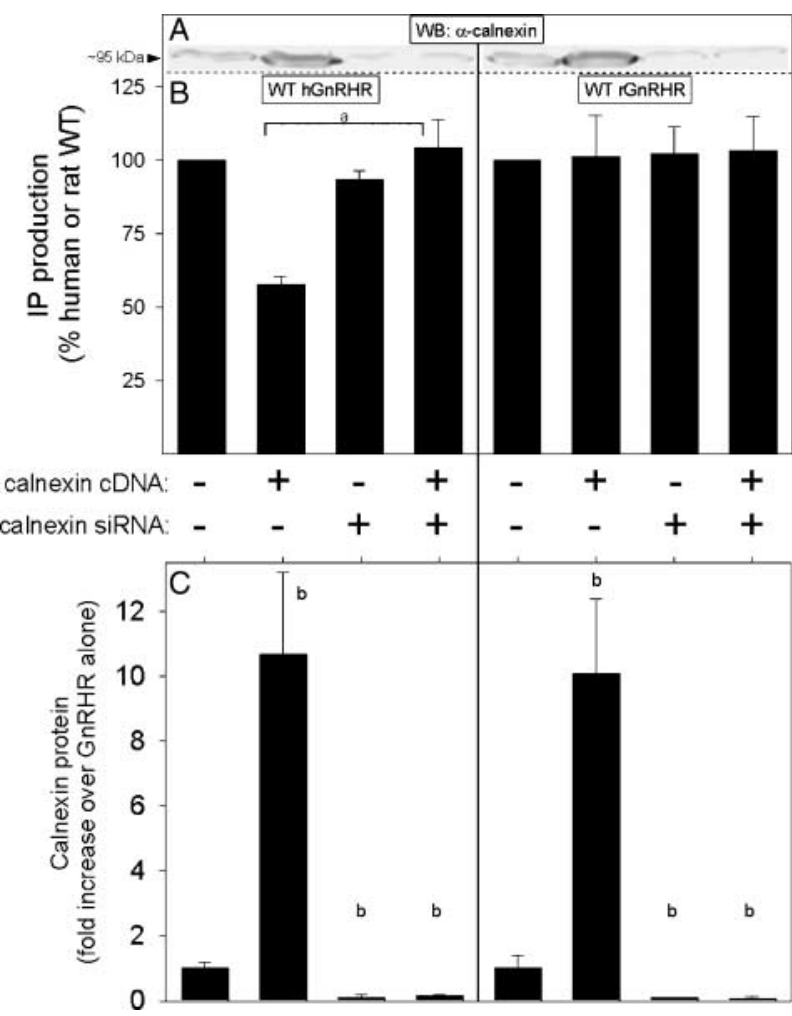

Figure 4 siRNA knockdown of calnexin mRNA and confirmation of protein expression levels. (A) Western blots with an anticalnexin antibody of cells transfected with control (non-targeting) or calnexin siRNA co-transfected with the human or rat WT GnRH receptors. Arrow indicates a molecular weight of $95 \mathrm{kDa}$, the approximate apparent molecular weight of calnexin in a western blot. (B) IP production from cells transfected with control (nontargeting) or calnexin siRNA co-transfected with the human or rat WT GnRH receptors. (C) Quantification of western blots. Western blot optical densities were measured using $\mathrm{NIH}$ image 1·62. Blots from three separate experiments, such as the one shown in (A), were averaged and graphed as fold increase compared with WT GnRHR transfected cells. In the presence of siRNA, there is 85$90 \%$ reduction in calnexin protein. ('a' indicates $P<0.05$; 'b' indicates $P<0.05$ compared with WT GnRHR transfected cells).

\section{Rat and human calnexin have similar effects on the human and rat GnRHR}

Human or rat calnexin was co-transfected with human or rat WT GnRHR. Rat calnexin had a similar effect on IP production from those receptors when compared with receptors co-expressed with human calnexin (not shown).

\section{Mutational analysis of consensus PKC sites in calnexin}

Mutations were made at two reported carboxyl terminal protein kinase $\mathrm{C}(\mathrm{PKC})$ consensus phosphorylation sites in calnexin $\left(\mathrm{S}^{504} \mathrm{~A}, \mathrm{~S}^{583} \mathrm{~A}\right.$, or both $\left.\mathrm{S}^{504} \mathrm{~A} / \mathrm{S}^{583} \mathrm{~A} ; 31\right)$. Mutation of $\mathrm{S}^{504}$ to Ala in calnexin (calnexin $\left(\mathrm{S}^{504} \mathrm{~A}\right)$ ) and co-transfection with the human GnRHR caused 

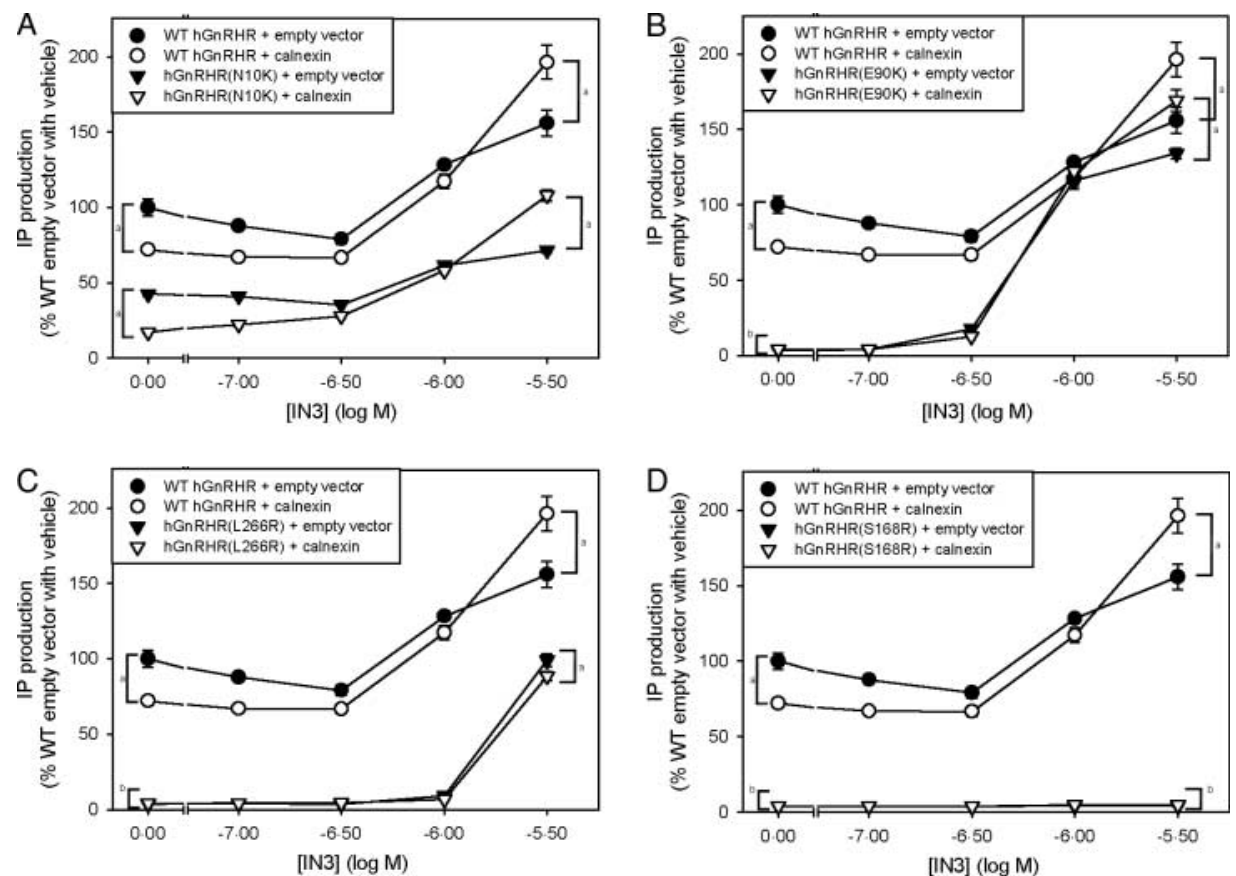

Figure 5 IP production of $\mathrm{GnRH}$ receptor mutants isolated from patients with hypogonadotropic hypogonadism in response to saturating ligand. (A) The partially expressed and fully rescuable by IN3 $h G n R H R\left(N^{10} K\right),(B)$ the non-expressed, fully rescuable $h G n R H R\left(E^{90} K\right),(C)$ the non-expressed, partially rescuable $h G n R H R\left(L^{266} R\right)$, and (D) the non-expressed non-rescuable $h G n R H R\left(S^{168} R\right)$ were co-transfected with empty vector cDNA or WT calnexin cDNA, then treated with increasing concentrations of IN3 and IP production was measured in response to $100 \mathrm{nM}$ Buserelin. The WT responses were repeated in each graph for clarity. ('a' indicates $P<0.05$; 'b' indicates $P>0.05$ ).

decreased GnRHR signaling in both the absence and the presence of IN3, compared with cells co-transfected with either empty vector or WT calnexin (Fig. 7). Neither mutation of $\mathrm{S}^{583}$ to Ala (calnexin $\left(\mathrm{S}^{583} \mathrm{~A}\right)$ ) nor mutation of both $\mathrm{S}^{504}$ and $\mathrm{S}^{583}$ to Ala (calnexin $\left(\mathrm{S}^{504} \mathrm{~A}\right.$ / $\left.\mathrm{S}^{583} \mathrm{~A}\right)$ ) changed the observable calnexin effect on IP production (not shown).

\section{Discussion}

Calnexin is a component of the QCS of the ER. Since a proportion of the human GnRHR is retained in the ER (Janovick et al. 2002, Brothers et al. 2004), we examined the possibility that calnexin may mediate ER retention of the GnRHR. Further, since the rat GnRHR appears to be more efficiently trafficked to the plasma membrane than the human GnRHR, we compared the effect of calnexin on these receptors as well. Expression of the human WT GnRHR with calnexin decreased receptor expression by about half, diminishing receptormediated second messenger production. The rat receptors were also retained by calnexin but, since a larger proportion of the rat GnRHR normally reaches the plasma membrane, there was no effect on maximal receptor signaling. Calnexin appears to retain a proportion of both human and rat GnRHRs in the ER, likely by means of a physical interaction between the proteins.

In the presence of a pharmacoperone, there is a calnexin-mediated increase in human GnRHR signaling, likely reflecting an increase in PME, although PME could not be directly measured after pharmacoperone treatment likely due to residual pharmacoperone. The pharmacoperone-stabilized receptors seemed to be more efficiently routed to the plasma membrane. Calnexin appears to act as a quality control protein for the GnRHR by retaining misfolded receptors and steering properly folded receptors to the plasma membrane.

Calnexin did not affect rat receptor-mediated maximal IP production either with or without the pharmacoperone when expressed with similar amounts of cDNA as the human receptor, an interesting observation when considering that calnexin mediated a $40 \%$ reduction in rat receptor PME. This effect was not due to the species difference between human and rat calnexin proteins. Nearly, all of the rat GnRHR is properly folded and expressed at the plasma membrane (Lin et al. 1998, Arora et al. 1999, Maya-Nunez et al. 2000); such very high expression is consistent with the observations that the rat receptor is not rescued with 

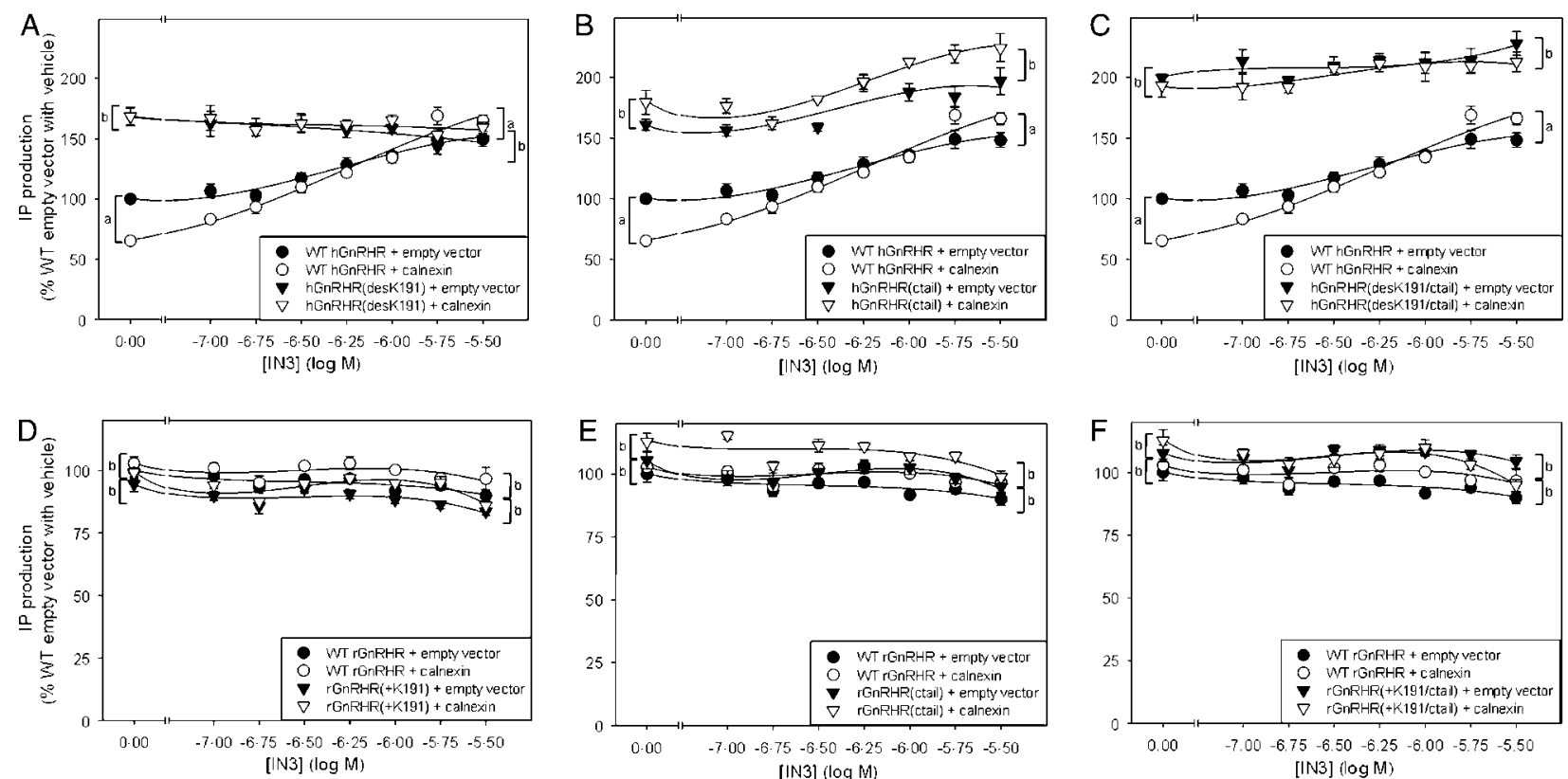

Figure 6 IP response from human or rat $\mathrm{GnRH}$ receptors with $\mathrm{K}^{191}$ and/or c-tail modifications. (A) WT human GnRHR and hGnRHR(desK $\left.{ }^{191}\right)$ were co-transfected with empty vector or calnexin, then treated with increasing concentrations of the pharmacoperone, IN3. (B) WT human GnRHR and hGnRHR(c-tail) were co-transfected with empty vector or calnexin, then treated with increasing concentrations of the pharmacoperone, IN3. (C) WT human GnRHR and hGnRHR(desK ${ }^{191} / \mathrm{c}$-tail) were co-transfected with empty vector or calnexin, then treated with increasing concentrations of the pharmacoperone, IN3. (D)- $(F) \mathrm{K}^{191}$ or the c-tail or both were added to the rat GnRHR and co-transfected with empty vector or calnexin, then treated with increasing concentrations of IN3 (A)-(F). The WT responses were repeated in each graph for clarity. IP production was measured in response to $100 \mathrm{nM}$ Buserelin. ('a' indicates $P<0 \cdot 05$; ' $b$ ' indicates $P>0.05)$.

pharmacoperone. Only when the cDNA of rat receptor was decreased $12 \cdot 5$-fold, did the additional calnexin decrease maximal IP production.

Addition of the non-mammalian c-tail or deletion of $\mathrm{K}^{191}$ from the human GnRHR dramatically increases plasma membrane expression in both cases (Lin et al. 1998, Maya-Nunez et al. 2000, Leanos-Miranda et al. 2003). Calnexin co-expression with human GnRHRs with the c-tail or without $\mathrm{K}^{191}$ no longer affected signaling. Thus, either calnexin does not interact with these receptors, or, more likely, any reduction in PME did not diminish IP production, as is seen with the rat GnRHR. The c-tail is important in PME since its presence reduces internalization rates resulting in increased PME (Willars et al. 1999, Brothers et al. 2002). Here, the c-tail also functions to increase the stability of the receptor, allowing increased PME.

Calnexin $\left(S^{504} \mathrm{~A}\right)$ reduced the signaling output of the human GnRHR both in the presence and the absence of pharmacoperone. Phosphorylation of this residue may decrease the ability of calnexin to retain the GnRHR. The effect of calnexin $\left(\mathrm{S}^{583} \mathrm{~A}\right)$ or calnexin $\left(\mathrm{S}^{504} \mathrm{~A} / \mathrm{S}^{583} \mathrm{~A}\right)$ on the human GnRHR appeared not different from the WT calnexin. Roderick et al. (2000) found that de-phosphorylation of $\mathrm{S}^{583}$, mediated by IP-stimulated $\mathrm{Ca}^{++}$mobilization, allowed greater expression of sarco-ER calcium ATPase (Wong et al. 1998). In agreement with their results, removal of the PKC consensus phosphorylation site $S^{583}$ (replaced with Ala) allowed greater expression of the human GnRHR, but only when $S^{504}$ was also mutated to Ala. The two

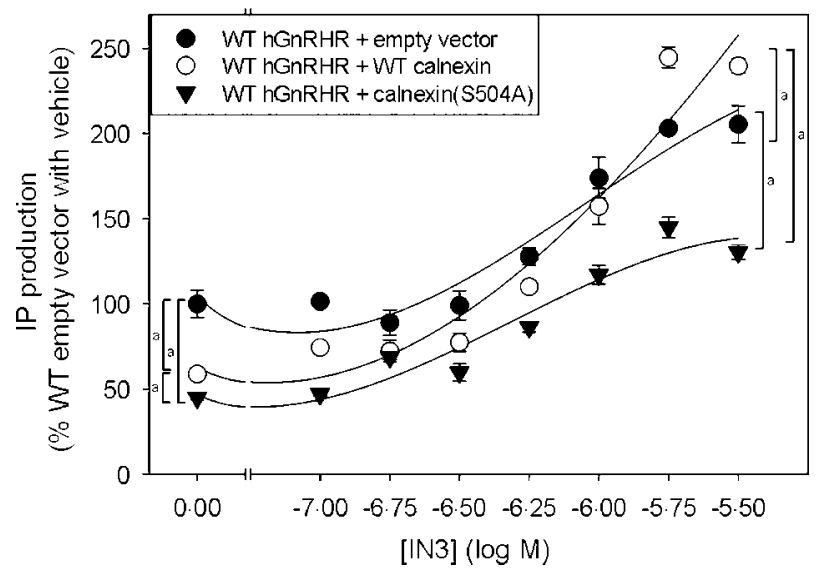

Figure 7 Effect of calnexin PKC consensus phosphorylation site mutant on regulation of GnRHR-mediated IP production. WT human GnRHR was co-transfected with empty vector, calnexin or calnexin $\left(S^{504} A\right)$ then treated with increasing concentrations of IN3. IP production was measured in response to $100 \mathrm{nM}$ Buserelin. ('a' indicates $P<0.05$ ). 
PKC phosphorylation sites in the carboxyl terminus of calnexin appear to have opposing roles in the retention of proteins, such as the GnRHR.

Calnexin is a lectin-like protein that binds to newly glycosylated proteins in the ER; therefore, it is likely that the calnexin-GnRHR interaction involves one or more of the glycosylated residues in the receptor $\left(\mathrm{Asn}^{18}\right.$ and $\mathrm{Asn}^{102}$; Davidson et al. 1995). However, when the $\mathrm{Asn}^{18}$ was mutated, the receptor was not expressed at the plasma membrane, and when the $\mathrm{Asn}^{102}$ was mutated, that receptor appeared identical to the wildtype receptor. Therefore, it was not possible to address the action of calnexin on these mutants (data not shown). Likely, glycosylated $\mathrm{Asn}^{18}$ is needed to mediate the interaction.

Like virtually all cells, the COS-7 cells used in this study express endogenous calnexin (Allen et al. 2001). When siRNA was used to knock down the transfected calnexin, the human GnRHR signaling was restored. Calnexin siRNA had little effect on the already robust rat GnRHR signaling. The siRNA targeting human calnexin did not knock down calnexin protein to undetectable levels. Several reasons might explain this initially surprising result. First, since the transfection efficiency is less than $100 \%$ (i.e., some cells may not have received siRNA), cells that express the receptor may not have also gotten calnexin siRNA and may express the calnexin protein. Further, it is well known that there is redundancy in protein quality control systems in the ER. One example, calreticulin, has been reported to have a nearly identical action on protein quality control as calnexin (Schrag et al. 2003). It is possible that calreticulin, and potentially other chaperone proteins in the ER, also act on the GnRHR. Finally, there is not full knockdown of the calnexin protein, as seen after quantification of the western blots, 10-15\% of calnexin remains in the cell population. Sequence variations between the human and the African green monkey (COS-7 cell) calnexin nucleotide sequences may preclude complete siRNA knockdown.

Though GnRHR expression varies widely throughout the menstrual cycle, it is possible, that receptor expression is lower in vivo than in our model. Nonetheless, we chose to use COS-7 cells in this study for a number of reasons, principally that these cells produce a large quantity of protein from transfected cDNA, thus increasing the burden on the ER and saturating endogenous calnexin.

The effect of pharmacoperone and the observation that misfolded human mutant GnRHRs are retained by calnexin suggesting that this protein chaperone recognizes misfolded proteins. In addition to showing that a proportion of the WT human GnRHR are retained by calnexin, our studies also suggest phosphorylation-dependant regulation of GnRHR PME by calnexin. The increased control over the human
GnRHR signaling may be advantageous when regulating the complicated human reproductive cycle but prove disadvantageous when mutations are introduced, as in hypogonadotropic hypogonadism.

\section{Acknowledgements}

We thank P E Knollman, and Drs C Brothers, J D Hennebold, W R Skach, and R L Stouffer for comments on the manuscript and Jo Ann Binkerd for formatting the manuscript. This work was supported by HD-19899, RR-00163, and HD-18185. All authors affirm that there is no conflict of interest that would prejudice the impartiality of this original work.

\section{References}

Allen S, Goodeve AC, Peake IR \& Daly ME 2001 Endoplasmic reticulum retention and prolonged association of a von Willebrand's disease-causing von Willebrand factor variant with ERp57 and calnexin. Biochemical and Biophysical Research Communications $280448-453$.

Arora KK, Chung HO \& Catt KJ 1999 Influence of a species-specific extracellular amino acid on expression and function of the human gonadotropin-releasing hormone receptor. Molecular Endocrinology 13 890-896.

Brothers SP, Janovick JA, Maya-Nunez G, Cornea A, Han XB \& Conn PM 2002 Conserved mammalian gonadotropin-releasing hormone receptor carboxyl terminal amino acids regulate ligand binding, effector coupling and internalization. Molecular and Cellular Endocrinology 190 19-27.

Brothers SP, Janovick JA \& Conn PM 2003 Unexpected effects of epitope and chimeric tags on gonadotropin-releasing hormone receptors: implications for understanding the molecular etiology of hypogonadotropic hypogonadism. Journal of Clinical Endocrinology and Metabolism 88 6107-6112.

Brothers SP, Cornea A, Janovick JA \& Conn PM 2004 Human lossof-function gonadotropin-releasing hormone receptor mutants retain wild-type receptors in the endoplasmic reticulum: molecular basis of the dominant-negative effect. Molecular Endocrinology 18 1787-1797.

Castro-Fernandez C, Janovick JA, Brothers SP, Fisher RA, Ji TH \& Conn PM 2002 Regulation of RGS3 and RGS10 palmitoylation by GnRH. Endocrinology 143 1310-1317.

Castro-Fernandez C, Maya-Nunez G \& Conn PM 2005 Beyond the signal sequence: protein routing in health and disease. Endocrine Reviews 26 479-503.

Conn PM, Janovick JA, Braden TD, Maurer RA \& Jennes L 1992 SIIp: a unique secretogranin/chromogranin of the pituitary released in response to GnRH. Endocrinology 130 3033-3040.

Conn PM, Leanos-Miranda A \& Janovick JA 2002 Protein origami: therapeutic rescue of misfolded gene products. Molecular Interventions 2 308-316.

Couzin J 2002 Protein structure. Harmless proteins twist into troublemakers. Science 296 28-29.

Davidson JS, Flanagan CA, Zhou W, Becker II, Elario R, Emeran W, Sealfon SC \& Millar RP 1995 Identification of $N$-glycosylation sites in the gonadotropin-releasing hormone receptor: role in receptor expression but not ligand binding. Molecular and Cellular Endocrinology 107 241-245.

Ellgaard L \& Frickel EM 2003 Calnexin, calreticulin, and ERp57: teammates in glycoprotein folding. Cell Biochemistry and Biophysics 39 223-247. 
Firestone GL \& Winguth SD 1990 Immunoprecipitation of proteins. Methods in Enzymology 182 688-700.

Gavel Y \& von Heijne G 1990 Sequence differences between glycosylated and non-glycosylated Asn-X-Thr/Ser acceptor sites: implications for protein engineering. Protein Engineering 5 433-442.

Hebert DN, Foellmer B \& Helenius A 1996 Calnexin and calreticulin promote folding, delay oligomerization and suppress degradation of influenza hemagglutinin in microsomes. EMBO Journal $\mathbf{1 5}$ 2961-2968.

Huckle WR \& Conn PM 1987 Use of lithium ion in measurement of stimulated pituitary inositol phospholipid turnover. Methods in Enzymology 141 149-155.

Janovick JA, Maya-Nunez G \& Conn PM 2002 Rescue of hypogonadotropic-causing and manufactured GnRH receptor mutants by a specific protein-folding template: misrouted proteins as a novel disease etiology and therapeutic target. Journal of Clinical Endocrinology and Metabolism 87 3255-3266.

Janovick JA, Ulloa-Aguirre A \& Conn PM 2003 Evolved regulation of gonadotropin-releasing hormone receptor cell surface expression. Endocrine 22 317-327.

Janovick JA, Knollman PE, Brothers SP, Ayala-Yanez R, Aziz AS \& Conn PM 2006 Regulation of G protein-coupled receptor trafficking by inefficient plasma membrane expression: molecular basis of an evolved strategy. Journal of Biological Chemistry 281 8417-8425.

Kleizen B \& Braakman I 2004 Protein folding and quality control in the endoplasmic reticulum. Current Opinion in Cell Biology 16 343-349.

Klotz IM 1982 Numbers of receptor sites from Scatchard graphs: facts and fantasies. Science 217 1247-1249.

Knollman PE, Janovick JA, Brothers SP \& Conn PM 2005 Parallel regulation of membrane trafficking and dominant-negative effects by misrouted GnRH receptor mutants. Journal of Biological Chemistry 280 24506-24514.

Leanos-Miranda A, Ulloa-Aguirre A, Ji TH, Janovick JA \& Conn PM 2003 Dominant-negative action of disease-causing gonadotropinreleasing hormone receptor (GnRHR) mutants: a trait that potentially coevolved with decreased plasma membrane expression of GnRHR in humans. Journal of Clinical Endocrinology and Metabolism 88 3360-3367.

Lin X, Janovick JA, Brothers S, Blomenrohr M, Bogerd J \& Conn PM 1998 Addition of catfish gonadotropin-releasing hormone (GnRH) receptor intracellular carboxyl-terminal tail to rat $\mathrm{GnRH}$ receptor alters receptor expression and regulation. Molecular Endocrinology 12 $161-171$.

Liu Y, Choudhury P, Cabral CM \& Sifers RN 1999 Oligosaccharide modification in the early secretory pathway directs the selection of a misfolded glycoprotein for degradation by the proteasome. Journal of Biological Chemistry 274 5861-5867.

Maya-Nunez G, Janovick JA \& Conn PM 2000 Combined modification of intracellular and extracellular loci on human gonadotropinreleasing hormone receptor provides a mechanism for enhanced expression. Endocrine 13 401-407.
Molinari M, Calanca V, Galli C, Lucca P \& Paganetti P 2003 Role of EDEM in the release of misfolded glycoproteins from the calnexin cycle. Science 299 1397-1400.

Oda Y, Hosokawa N, Wada I \& Nagata K 2003 EDEM as an acceptor of terminally misfolded glycoproteins released from calnexin. Science 299 1394-1397.

Roderick HL, Lechleiter JD \& Camacho P 2000 Cytosolic phosphorylation of calnexin controls intracellular $\mathrm{Ca}(2+)$ oscillations via an interaction with SERCA2b. Journal of Cell Biology 149 1235-1248.

Schrag JD, Procopio DO, Cygler M, Thomas DY \& Bergeron JJ 2003 Lectin control of protein folding and sorting in the secretory pathway. Trends in Biochemical Sciences 28 49-57.

Sealfon SC, Weinstein H \& Millar RP 1997 Molecular mechanisms of ligand interaction with the gonadotropin-releasing hormone receptor. Endocrine Reviews 2 180-205.

Seminara SB, Hayes FJ \& Crowley WF Jr 1998 Gonadotropin-releasing hormone deficiency in the human (idiopathic hypogonadotropic hypogonadism and Kallman's syndrome): pathophysiological and genetic considerations. Endocrine Reviews 19 521-539.

Tjoelker LW, Seyfried CE, Eddy RL Jr, Byers MG, Shows TB, Calderon J, Schreiber RB \& Gray PW 1994 Human, mouse, and rat calnexin cDNA cloning: identification of potential calcium binding motifs and gene localization to human chromosome 5. Biochemistry 11 3229-3236.

Ulloa-Aguirre A, Janovick JA, Brothers SP \& Conn PM 2004 Pharmacologic rescue of conformationally-defective proteins: implications for the treatment of human disease. Traffic 5 821-837.

Vassilakos A, Michalak M, Lehrman MA \& Williams DB 1998 Oligosaccharide binding characteristics of the molecular chaperones calnexin and calreticulin. Biochemistry 37 3480-3490.

Willars GB, Heding A, Vrecl M, Sellar R, Blomenrohr M, Nahorski SR \& Eidne KA 1999 Lack of a C-terminal tail in the mammalian gonadotropin-releasing hormone receptor confers resistance to agonist-dependent phosphorylation and rapid desensitization. Journal of Biological Chemistry 42 30146-30153.

Wong HN, Ward MA, Bell AW, Chevet E, Bains S, Blackstock WP Solari R, Thomas DY \& Bergeron JJ 1998 Conserved in vivo phosphorylation of calnexin at casein kinase II sites as well as a protein kinase C/proline-directed kinase site. Journal of Biological Chemistry 27 17227-17235.

Zhu BT 1993 The competitive and noncompetitive antagonism of receptor-mediated drug actions in the presence of spare receptors. Journal of Pharmacological and Toxicological Methods 29 85-91.

Received 25 July 2006

Accepted 24 August 2006 